Doi: https://doi.org/10.24036/jha.0102.2019.07

\title{
Spelling Bee Competition Trophy Rector of Bina Darma 2018
}

\author{
${ }^{1}$ Ferry Kurniawan, ${ }^{2}$ Sunda Ariana, ${ }^{3}$ Rosmaidar \\ ${ }^{123}$ Fakultas Bahasa dan Sastra / Sastra Inggris, Universitas Bina Darma \\ Email: ferry.kurniawan@binadarma.ac.id ${ }^{1}$ sunda_ariana@binadarma.ac.id ${ }^{2}$, \\ rosmaidar@binadarma.ac.id ${ }^{3}$
}

\begin{abstract}
Global competition has demanded every individual to have strong competitiveness on a national and international scale. Proficiency in language is also a demand in global competition. Language is also a medium that can influence someone and is a media used to express opinions and analyze problems. As a lecturer who takes shelter in the English study program, there is a desire to conduct guidance in the language field for lecturers and employees of Bina Darma University as one of the community service activities. Therefore Bujang Girls Campus Bina Darma University was chosen to conduct Spelling Bee Competition activities to provide motivation to learn English for lecturers and employees of Bina Darma University .. The mission of the Spelling Bee Comepetion activity is to provide additional knowledge of English which is expected to be able to increase English proficiency for Bina Darma University lecturers and employee.
\end{abstract}

Keywords: Spelling, Bee, Competition

Abstrak

Persaingan global telah menuntut setiap individu untuk mempunyai daya saing yang kuat baik dalam skala nasional maupun internasional. Mahir berbahasa juga merupakan suatu tuntutan dalam persaingan global. Bahasa juga merupakan suatu media yang dapat mempengaruhi seseorang dan merupakan media yang dipergunakan untuk menyampaikan pendapat serta menganalisa masalah. Sebagai dosen yang bernaung di program studi Bahasa Inggris timbul keinginan untuk melakukan pembinaan di bidang Bahasa bagi dosen dan karyawan Universitas Bina Darma sebagai salah satu kegiatan pengabdian masyarakat. Oleh karena itu dipilihlah Ikatan Bujang Gadis Kampus Universitas Bina Darma untuk dilakukan Kegiatan Spelling Bee Competition untuk memberikan motivasi belajar belajar Bahasa Inggris bagi dosen dan karyawan Universitas Bina Darma.. Misi dari kegiatan Spelling Bee Comepetion ini yaitu memberikan tambahan pengetahuan bahasa inggris yang diharapkan mampu meningkatan kemampuan Bahasa Inggris bagi dosen dan karyawan Universitas Bina Darma..

Keywords: Spelling Bee, Kompetisi

\section{ANALISIS SITUASI}

Dalam mencerdaskan kehidupan bangasa banyak kiat yang dapat kita lakukan agar terealisasi dengan optimal. Tidak hanya kita Negara melalui pemerintan telah berupaya untuk mewujudkannya. Upaya yang dapat dilakukan oleh Negara untuk menghadapi tantangan global salah satunya dengan menyiapkan Sumber Daya Manusia (SDM) yang handal, Bakhtiar Dkk (2019). Pendidikan merupakan media nyata dalam menciptakan dan mewujudkan upaya dari Negara melalui pemerintah. Salahsatu upaya meningkatkan mutu pendidikan adalah dengan dimanfaatkannya berbagai macam sumber belajar dalam kegiatan pembelajaran. Peningkatan mutu itu akan terlaksana dengan baik jika sarana dan prasarana pendidikan, media pendidikan dan peran serta guru di dalamnya, Redawati, R., \& Asnaldi, A. (2017).

Bahasa juga merupakan suatu media dalam mengaplikasikan konten dalam proses pendidikan. Dalam kontek khusus bahasa dapat mempengaruhi seseorang dan merupakan media yang dipergunakan untuk menyampaikan pendapat serta menganalisa masalah. Oleh karena itu, bahasa dikategorikan sebagai salah satu bidang akademis di perguruan tinggi atau universitas. Banyak hal dapat dilakukan untuk mengasah kemampuan seseorang dalam berbahasa antara lain adalah penulisan novel, pembacaan puisi, dan debat. 
Dalam dunia debat, setiap individu dituntut untuk menjadi lebih kritis dalam menganalisa setiap permasalahan yang mereka hadapi. Oleh karena itu, perguruan tinggi dan universitas mempunyai peranan yang sangat penting dalam hal membentuk sikap berpikir kritis dan logis. Salah satu cara yang sudah dijalankan oleh masing - masing universitas dan perguruan tinggi adalah dengan menggalakan program debat bahasa Inggris. Melalui penguasaan berdebat menggunakan bahasa Inggris itu berarti melatih mahasiswa dalam penguasaan bahasa dan juga melatih mahasiswa untuk menarik kesimpulan dan menyampaikan ide serta membuat keputusan dari semua pengetahuan global yang mereka miliki terhadap suatu permasalahan.

Salah satu debat yang sangat populer adalah debat bahasa Inggris, karena selain belajar menganalisa debat bahasa Inggris juga mengajarkan berbahasa asing. Selain itu, Debat Bahasa Inggris sudah dipercayai menjadi sebuah sarana yang tepat dalam mengasah kemampuan menganalisa, menyimpulkan, menyampaikan ide dan membuat keputusan dari semua pengetahuan global yang mahasiswa miliki. Hal inilah yang mendasari pemikiran bahwa, penguasaan seseorang dalam berdebat dapat memfasilitas mahasiswa dalam bersaing untuk menjadi Sumber Daya Manusia yang handal dalam kancah nasional maupun internasional.

Di Indonesia, debat berbahasa Inggris telah berkembang pesat. Berbagai kompetisi debat berbahasa Inggris telah banyak diadakan dan diikuti oleh sebagian besar perguruan tinggi di Indonesia. Universitas Bina Darma sebagai salah satu perguruan tinggi swasta yang berkembang di Palembang pun turut ambil bagian dalam berbagai kompetisi debat berbahasa Inggris, baik di dalam maupun di luar negeri. Kali ini, Universitas Bina Darma berniat menyelenggarakan Bina Darma Rector's Trophy 2017 (BDR) yang merupakan kompetisi debat berbahasa Inggris antar program studi yang ada di Universitas Bina Darma.

Menilik keberhasilan Bidar REDC 2009 dan Bina Darma Rector's Trophy, Bidar Debating Union selaku unit kegiatan mahasiswa dibawah naungan Language Centre Universitas Bina Darma Palembang merasakan perlunya mengadakan BDR's Trophydalam ruang lingkup internal Universitas Bina Darma. Hal ini bertujuan untuk mencari bakat-bakat, meningkatkan kualitas berbahasa Inggris, serta membantu mahasiswa dan mahasiswi Universitas Bina Darma Palembang agar dapat berpikir kritis dan kreatif serta berani mengemukakan pendapatnya. Harapan kami, BDR's Trophy 2017 ini dapat menjadi acara tahunan yang bergengsi bagi mahasiswa dan mahasiswi Universitas Bina Darma untuk terus mengembangkan kemampuan debat berbahasa Inggris yang sangat bermanfaat di era globalisasi.

Ditahun ini adalah tahun ke-2 diadakannya Spelling Bee Competition. Ditahun pertama perlobaan ini dilaksanakan bagi Dosen dan Karyawan Universitas Bina Darma, begitu juga di tahu yang kedua ini. Diharapkan Nantinya setiap tahun perlombaan ini akan terus dilaksanakan, bukan hanya untuk dosen dan karyawan saja tetapi juga bagi Mahsiswa/i Universitas Bina Darma.

\section{SOLUSI DAN TARGET}

\section{Solusi}

Solusi dari permasalahan di atas adalah dengan melakukan pendampingan kepada setiap mahasiswa baik secara langsung maupun tidak langsung di lingkungan Universitas Bina Darma. Pendampingan ini di mulai dengan memperkenalkan tujuan bahasa, manfaat menguasai bahasa, dan aplikasa dalam berbaahasa yang baik. Setelah mengetahui tentang bahasa, langkah selanjutnya adalah menjaring mahasiswa yang memiliki kompetensi yang baik guna diberdayakan sebagai tim debat pada Universitas Bina Darma.

\section{Target}

1. Memberikan motivasi dalam belajar dan menggunakan bahasa Ingggris di lingkungan Universitas Bina Darma.

2. Memberikan semangat berkompetisi di tingkat local.

3. Menjaring mahasiswa yang kompeten untuk berkompetisi di tingkat nasional maupun internasional.

\section{METODE PELAKSANAAN \\ Peserta Kegiatan}

Kegiatan ini diikuti oleh 13 orang dosen dan karyawan Universitas Bina Darma. Pelaksanaan kegiatan terdiri dari 3 babak, yaitu Babak Penyisihan, Babak Semi Final, dan Babak Final. Babak 


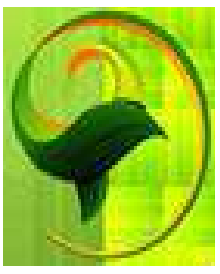

Journal Humanities: Jurnal Pengabdian kepada Masyarakat Volume 1, Nomor 1, Bulan Juni, 2020. E - ISSN 2715-5471

Doi: https://doi.org/10.24036/jha.0102.2019.07

penyisihan diikuti oleh seluruh peserta (13 orang). Dari 13 orang pserta terjaring 5 peserta yang masuk babak Semi Final. Dari 5 peserta ini dijaring 3 orang yang lolos masuk ke babak Final untuk memperebutkan Juara 1, 2, dan 3. 5 orang yang berhasil masuk ke babak Semi Final adalah:
1. Verawaty, SE., M.Si. AK., CA.
2. Citra Indah Merina, SE. AK., CA., MM.
3. Septiani Fransisca, SE., M.Si., AK.
4. Leon Andreti Abdilah, S.Kom., MM.
5. Septa Hardini, MT.

\subsection{Tempat dan Waktu Pelaksanaan}

Tempat

Hari:

Tanggal

Jam Pelaksanaan
: Kampus Utama Universitas Bina Darma

: Rabu dan Kamis

: 13-14 Dsemeber 2017

: 08:00-Selesai

Jadwal kegiatan diatur sebagai berikut:

Hari 01/ 13 Desember 2017

\begin{tabular}{|c|l|c|}
\hline No. & \multicolumn{1}{|c|}{ Kegiatan } & Ruangan \\
\hline 1 & Registrasi & 701 \\
\hline 2 & Babak Penyisihan & 701 \\
\hline 3 & Pengumuman Semi Finalist & 701 \\
\hline 4 & Babak Semi Final & 701 \\
\hline 5 & Pengumuman Finalis & 701 \\
\hline
\end{tabular}

Hari ke 2 / 14 Desember 2017

\begin{tabular}{|c|l|c|}
\hline No. & \multicolumn{1}{|c|}{ Kegiatan } & \multicolumn{1}{|c|}{ Ruangan } \\
\hline 1 & Pengundian Nomer urut Finalis & Hall lantai 2 Kampus Utama \\
\hline 2 & Babak Final & Hall lantai 2 Kampus Utama \\
\hline 3 & Clossing Ceremony dan pengumuman Pemenang & Hall lantai 2 Kampus Utama \\
\hline
\end{tabular}

a. Lama Kegiatan

Kegiatan Pengabdian ini berlangsung selama 44 .jam, dengan rincian kegiatan sebagai berikut:

\begin{tabular}{|c|c|c|c|}
\hline Tanggal & Waktu & Keterangan & Lama \\
\hline 10 Nov 2017 & $14: 00-16: 00$ & Rapat Perencanaan Kegiatan & $2 \mathrm{Jam}$ \\
\hline 20 Nov 2017 & 09:00-11:00 & Rapat Koordinasi pelaksanaan kegiatan & $2 \mathrm{Jam}$ \\
\hline $23-24$ Nov 2017 & $13: 00-18: 00$ & Pengumpulan Materi Lomba (kosakata) & $10 \mathrm{jam}$ \\
\hline 27 Nov. 2017 & $08: 00-12: 00$ & Rapat seleksi dan pemantapan materi & 4 jam \\
\hline 13 Des. 2017 & 08:00-15:00 & Pelaksanaan Kegiatan hari ke 1 & 8 jam \\
\hline 14 Des. 2017 & $08: 00-17: 00$ & Pelaksanaan Kegiatan hari ke 2 & 9 jam \\
\hline 21 Des. 2017 & 08:00-17:00 & Penulisan Laporan Pengabdian & 9 Jam \\
\hline \multicolumn{3}{|c|}{$\begin{array}{ll} & \text { TOTAL } \\
\end{array}$} & 44 jam \\
\hline
\end{tabular}


PELAKSANAAN KEGIATAN

Disertaidengan Dokumentasi Kegiatan Pengabdian)

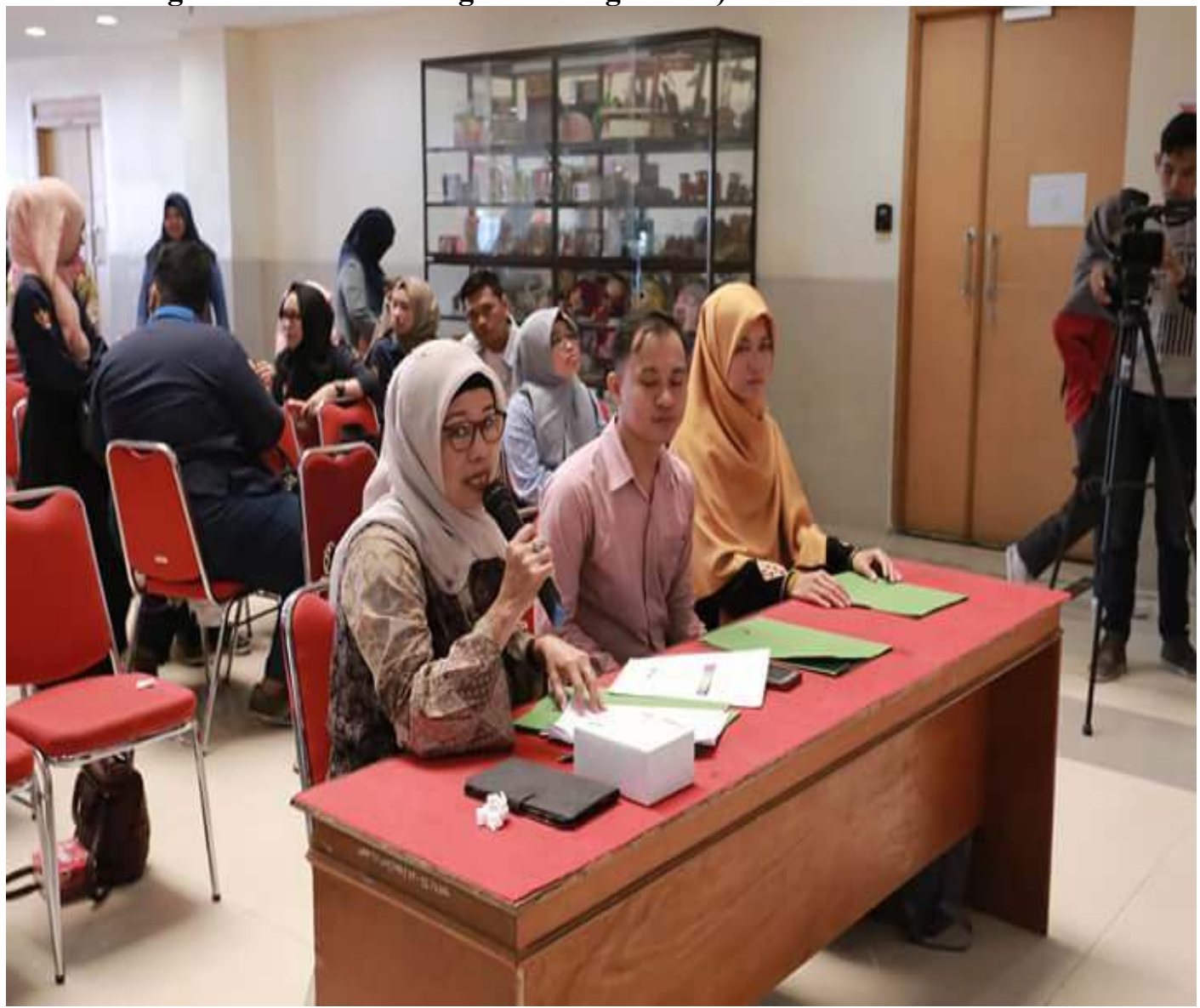

Gambar 1 Penjurian

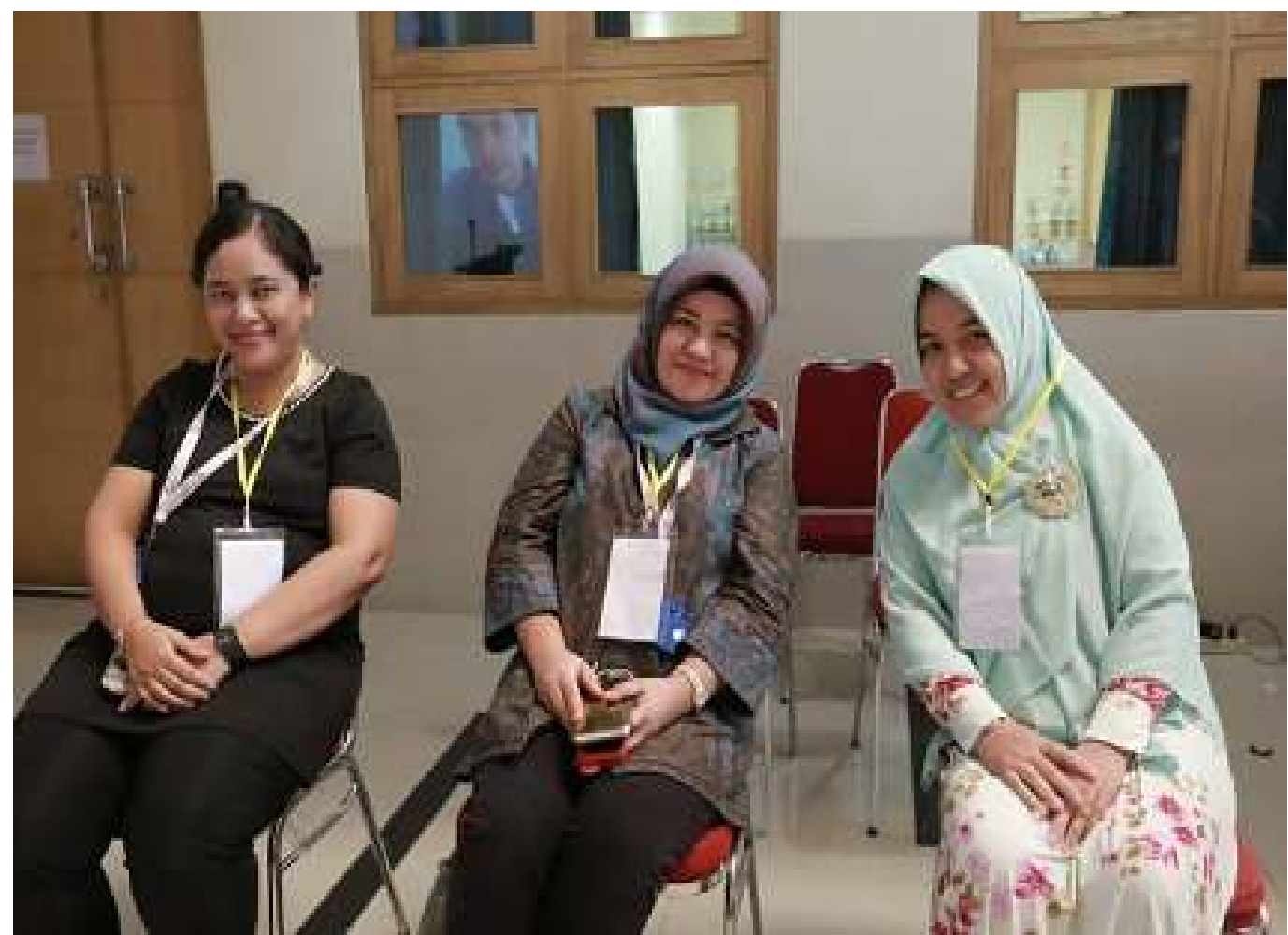


Journal Humanities: Jurnal Pengabdian kepada Masyarakat Volume 1, Nomor 1, Bulan Juni, 2020. E - ISSN 2715-5471 Doi: https://doi.org/10.24036/jha.0102.2019.07

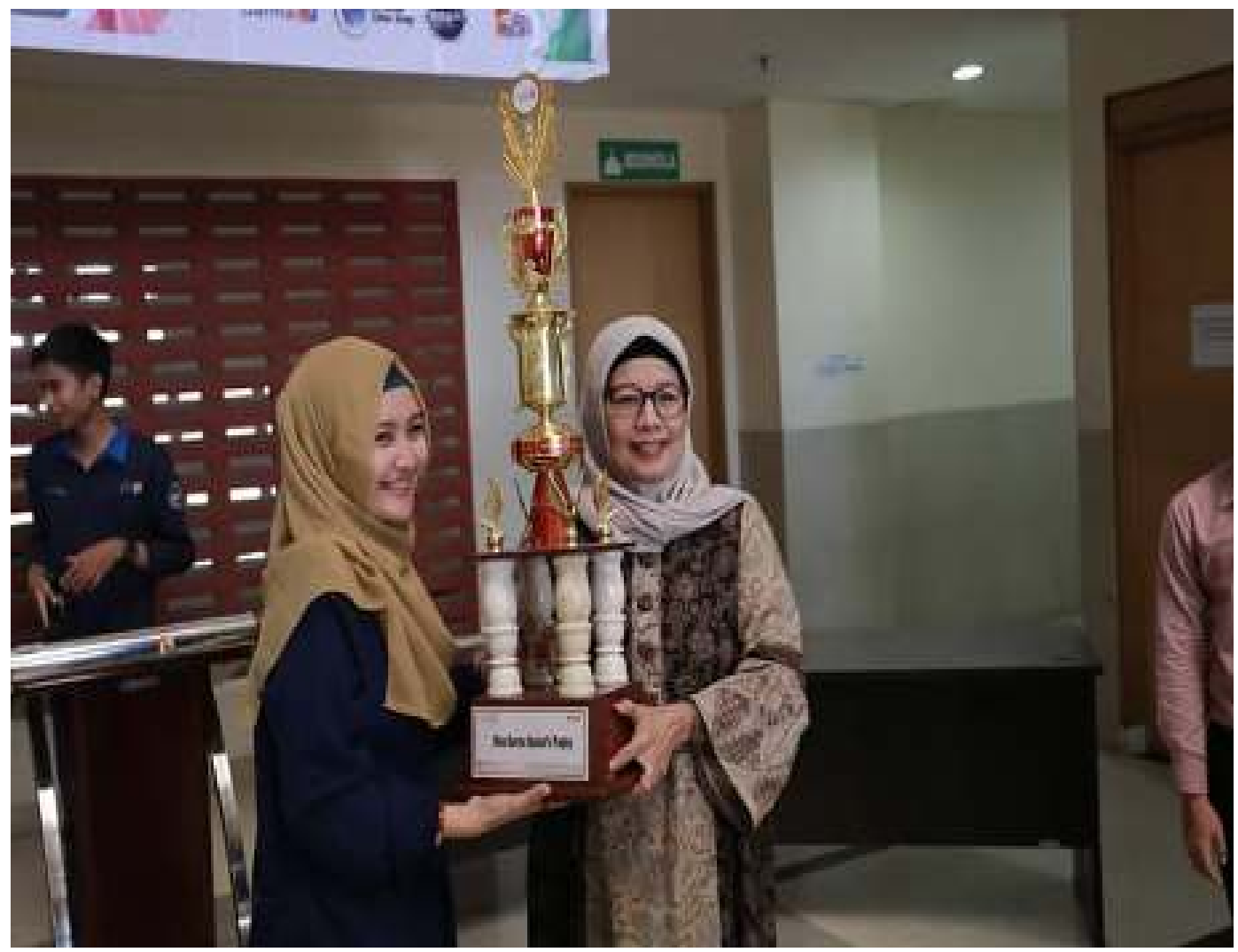

Gambar . 3 Panitia dan Peserta

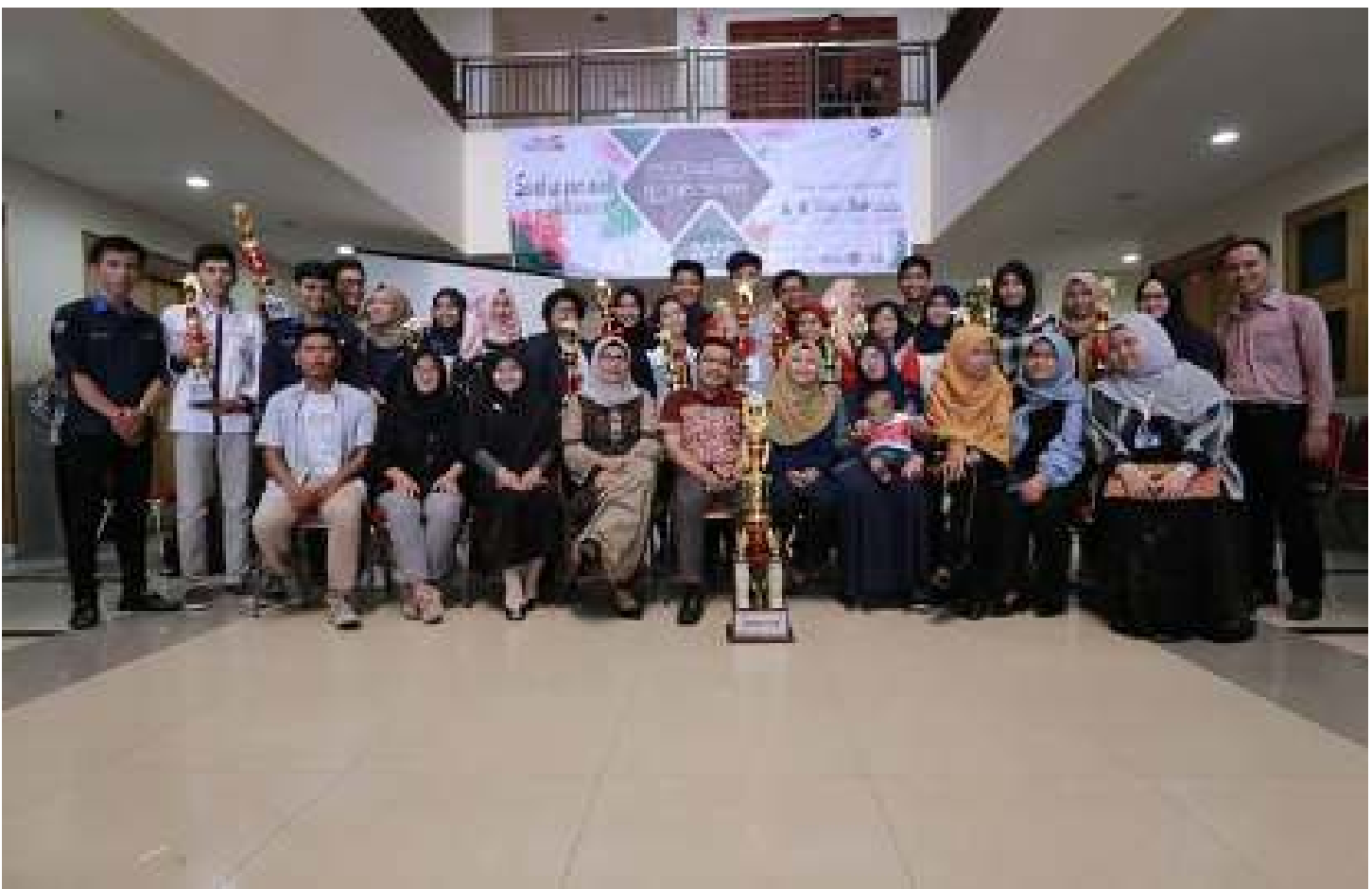

Gambar 4. Panitia dan peserta dalam kegiatan 


\section{HASIL DAN PEMBAHASAN} berikut:

Dari seleksi Babak Penyisihan, Babak Semifinal dan Babak Final, didapat hasil sebagai

1. Juara Pertama: Septiani Fransisca, SE., M. Si., AK. - Dosen Fakultas Ekonomi Universitas Bina Darma.

2. Juara Kedua: Verawaty, SE. M. Si. AK., CA. - Dosen Fakultas Ekonomi Universitas Bina Darma.

3. Juara Ketiga: Citra Indah Merina, SE. AK., CA., MM. - Dosen Fakultas Ekonomi Universitas Bina Darma.

Dosen dan karyawan Universitas Bina Darma memiliki potensi untuk terus berkembang dalam bidang kebahasaan dan juga pemikiran, sehingga perlu dibarengi dengan kegiatankegiatan yang fokus pada peningkatan kemampuan berbahasa Inggris mereka serta untuk memotivasi mereka dalam belajar dan menggunakan Bahasa Inggris di dalam maupun di luar lingkungan kampus. Spelling Bee Competition merupakan salah satu kegiatan yang cukup baik dalam memperkaya penguasaan kosakata bahasa Inggris - yang sangat bermanfaat dalam menunjang keterampilan berbahasa seseorang, yaitu keterampilan menyimak (listening), berbicara (speaking), membaca (reading), dan menulis (writing). Kegiatan Spelling Bee Competition yang akan datang diharapkan dapat diikuti oleh dosen, karyawan, dan mahasiswa di lingkungan dan di luar Universitas Bina Darma, sehingga kegiatan ini akan memberi manfaat terhadap pengembangan keterampilan berbahasa civitas akademika UBD khususnya, dan civitas akademika di luar UBD pada umumnya.

\section{KESIMPULAN}

Dosen dan karyawan Universitas Bina Darma memiliki potensi untuk terus berkembang dalam bidang kebahasaan dan juga pemikiran, sehingga perlu dibarengi dengan kegiatan-kegiatan yang fokus pada peningkatan kemampuan berbahasa Inggris mereka serta untuk memotivasi mereka dalam belajar dan menggunakan Bahasa Inggris di dalam maupun di luar lingkungan kampus. Spelling Bee Competition merupakan salah satu kegiatan yang cukup baik dalam memperkaya penguasaan kosakata bahasa Inggris - yang sangat bermanfaat dalam menunjang keterampilan berbahasa seseorang, yaitu keterampilan menyimak (listening), berbicara (speaking), membaca (reading), dan menulis (writing).

\section{PENGAKUAN}

Terima kasih saya ucapkan kepada Rektor Universitas Bina Darma, Tim English Learning Center (ELC) Universitas Bina Darma,

\section{DAFTAR PUSTAKA}

Bakhtiar, S., Oktarifaldi, O., \& Putri, L. P. (2019). Implementation of Learning and Fundamental Motor Skill Measurement of Early Childhood Motor Skill for PAUD Teachers in Padang Panjang City. Jurnal Humanities Pengabdian Kepada Masyarakat, 1(1), 36-47.

Bavel, R.K. 2010.The Effect Of Academic Optimism On Student Academic Achievement InAlabamma. Unpublished Dissertation.Tuscaloosa :Universitiy Of Alabamma

Direktorat Jenderal Pembelajaran dan Kemahasiswaan Kementeriaan Riset, Teknologi, dan Pendidikan Tinggi. 2016. Pedoman National University Debating Championship (2016). Jakarta, Indonesia: Direktorat Jenderal Pembelajaran dan Kemahasiswaan Riset Teknologi dan Pendidikan Tinggi 
Journal Humanities: Jurnal Pengabdian kepada Masyarakat Volume 1, Nomor 1, Bulan Juni, 2020. E - ISSN 2715-5471

Doi: https://doi.org/10.24036/jha.0102.2019.07

Holmes, E.A., Arntz, A., \&Smucker, M.R. 2011. Imagery rescripting in cognitive behaviourtherapy:Images, treatment techniques and outcomes. Journal of Behavior TherapymandExperimental Psychiatry, 38: 297-305. www.elsevier.com/locate/jbtep

Redawati, R., \& Asnaldi, A. (2017). Persepsi Guru-Guru Non Penjas terhadap Pembelajaran Pendidikan Jasmani Olahraga Kesehatan dan Rekreasi Gugus IV Sungai Jambu Kecamatan Pariangan. Sport Science, 17(1), 10-18.

Snider, Alfred. C. 2008. The Code of the Debater: Introduction to Policy Debating. New York, NY: International Debate Education Association.

Nathan, R. \& Hill, L. 2012.Konseling Karir. (TerjemahanHellyPrajitnoSoetjipto\& Sri MulyantiniSoetjipto).Yogyakarta :PustakaPelajar.

Supiani. 2016. The Implementation Of Process Approach To Teaching Writing At The Ninth GradeOf SMPN 1 Pelaihari Academic Year 2015/2016. Journal Nusantara of Research, 3: 1-12. 